\title{
THE EFFECT OF CREEP, OXIDATION AND CRYSTAL ORIENTATION \\ ON HIGH TEMPERATURE FATIGUE CRACK PROPAGATION \\ IN STANDARD AND RAFT-LIKE GAMMA PRIME CMSX-2
}

\author{
Valentino Lupinc, Giovanni Onofrio, and Gerardo Vimercati \\ CNR - ITM, Vai Induno 10, I-20092 Cinisello Balsamo, Italy
}

\begin{abstract}
The fatigue crack propagation (FCP) behaviour of $<001>$ axially oriented single edge notch (SEN) tension specimens $(\mathrm{R}=0.05)$ if $\mathrm{CMSX}-2$ has been examined. At $950^{\circ} \mathrm{C}$ $<100>$ oriented cracks propagate faster than $<110\rangle$ oriented cracks in the (001) plane.

The influence of $\gamma^{\prime}$ morphology on FCP at 750 and $950^{\circ} \mathrm{C}$ has been determined. Increasing the test temperature from 750 to $950^{\circ} \mathrm{C}$ lowers the FCP rates especially of the standard heat treated (ST) material (cuboidal $\gamma^{\prime}$ ). FCP rates of the thermomechanicaly treated (TMT) material, which has a raft-like $\gamma^{\prime}$ and which simulates the microstructure formed after short high temperature service, are not very sensitive to temperature variations between 750 and $950^{\circ} \mathrm{C}$. Higher FCP rates at $950^{\circ} \mathrm{C}$ for the TMT compared to the ST material have been related to fracture morphology.

Time dependent FCP mechanisms were explored at $950^{\circ} \mathrm{C}$ for cuboidal and raft-like $\gamma^{\prime}$ materials by performing continuous cycle (triangular wave form) and hold time tests. Hold time tests exhibited lower FCP rates. Tests in air had much slower FCP rates than tests in vacuum at low $\Delta \mathrm{K}$, especially with hold times. Repeatedly changing the environment from vacuum to air and vice versa, at $950^{\circ} \mathrm{C}$ with hold time provides confirmation of the slower propagation rates in air than in vacuum. Oxide-induced closure at the crack tip can explain the drastic environmental effect on FCP rates at low $\Delta \mathrm{K}$ values while creep mechanisms can explain the acceleration at high $\Delta \mathrm{K}$ when hold time is added in vacuum.
\end{abstract}

Superalloys 1992

Edited by S.D. Antolovich, R.W. Stusrud, R.A. MacKay,

D.L. Anton, T. Khan, R.D. Kissinger, D.L. Klarstrom

The Minerals, Metals \& Materials Society, 1992 


\section{Introduction}

The understanding of the detrimental effect of grain boundaries on creep properties of components operating at high temperature and the improvement in the directional solidification techniques have lead to the development of single crystal nickel base superalloys. These materials show longer creep life, higher ductility and strain controlled fatigue endurance, as well as better oxidation resistance when compared with equiaxed superalloys. Although no cavitation or grain boundary oxidation mechanisms, that have been widely reported to occur in polycrystal superalloys at elevated temperature when frequency is decreased or when a hold time is included in the fatigue cycle (1), are operative in this class of materials, oxidation and creep processes at the crack tip still remain the time dependent mechanisms that influence fatiguc crack propagation (FCP) rates.

Crompton and Martin (2) have studied FCP behaviour of MAR-M 002 in the $600-850^{\circ} \mathrm{C}$ temperature range and $10-0.1 \mathrm{~Hz}$ frequency range. In these experimental conditions they found very limited influence of test frequency on FCP rates, but higher $\triangle K$ threshold at the lower frequency. These results are consistent with an oxide induced closure process at the crack tip, more effective in the near threshold region.

The influence of $\gamma^{\prime}$ morphology on the low cycle fatigue behaviour of a model single crystal superalloy has been evaluated by Anton (3) in the $650-980^{\circ} \mathrm{C}$ temperature range. This author found no difference on cycle life to failure between raft-like and cuboidal $\gamma^{\prime}$. Instead, in CMSX-2 a marked weakening effect of raft-like $\gamma^{\prime}$ has been observed in creep (4-6). Hardly any results on the influence of raft-like $y^{\prime}$ microstructure on FCP rate have been found in literature. Such effect has been reported in CMSX-2 (6).

Initially the role played by secondary crystal orientation, i.c. the direction of crack advance in the $(001)$ plane ranging from $\langle 100\rangle$ to $\langle 110\rangle$, on FCP rate was not completely recognized. Howland and Brown (7) did not find any effect of secondary orientation on FCP rate in SRR 99 single crystal at room temperature. Diboine et al. (8) observed no such effect at $20^{\circ} \mathrm{C}$ in PWA 1480 single crystal single edge notch (SEN) specimens, while only a slight dependence was observed at $870^{\circ} \mathrm{C}$. On this basis the present authors measured FCP rate of $\langle 001\rangle$ axially oriented CMSX -2 specimens with random secondary orientation. But recent work by Defresne and Remy (9) on the same type of material has shown a marked secondary orientation influence on FCP rate at $650^{\circ} \mathrm{C}$, attributed mainly to more effective crack closure in $\langle 110\rangle$ than in the weak $<100\rangle$ direction. This new information cast serious doubts on the previously reported temperature and microstructure dependencies of FCP rates $(10,11,12)$.

The purpose of this work is to determine the temperature dependence of FCP rate in the 750$950^{\circ} \mathrm{C}$ range and to investigate the influence of creep and oxidation mechanisms on elevated temperature FCP behaviour of CMSX -2 single crystal, having both the standard cuboidal $\gamma^{\prime}$ microstructure and a raft-like $\gamma^{\prime}$ simulating a microstructure formed during service.
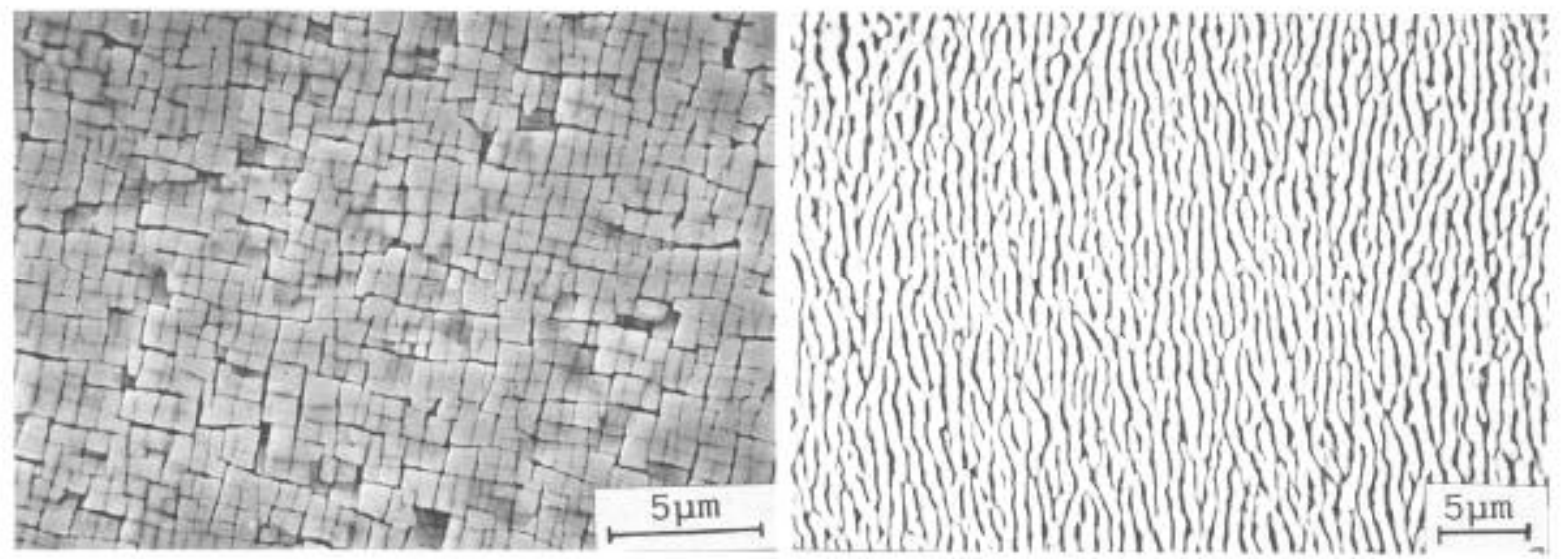

Figure 1 - Cuboidal $\gamma^{\prime}$ afte standard heat treatment (ST) and raft-like $\gamma^{\prime}$ after thermomechanical treatment (TMT). 
The specimens were loaded along $<001>$ direction and the influence of the secondary orientation (i.e. crack propagation direction) of SEN specimens on FCP rate at $950^{\circ} \mathrm{C}$ has also been quantified.

\section{$\underline{\text { Material and Experimental Procedure }}$}

The tested material was CMSX-2 single crystal cast and solution treated by Thyssen, Bochum, D. It was obtained in cylindrical bar form with $12 \mathrm{~mm}$ diameter and $160 \mathrm{~mm}$ length with the following chemical composition (wt. \%):

$$
\begin{array}{rcccccrr}
\mathrm{Cr} & \mathrm{Mo} & \mathrm{Ti} & \mathrm{Ta} & \mathrm{W} & \mathrm{Co} & \mathrm{Al} & \mathrm{Ni} \\
7.9 & 0.6 & 0.99 & 6.0 & 7.9 & 4.6 & 5.58 & \mathrm{bal} .
\end{array}
$$

The principal axis of the bars was within $6^{\circ}$ off the $<001>$ direction. The standard ageing heat treatment which was carried out at $1080^{\circ} \mathrm{C}$ for $4 \mathrm{~h}$ followed by $870^{\circ} \mathrm{C}$ for $20 \mathrm{~h}$ (ST) produced a $2 / 3$ volume fraction dispersion of cuboidal $\gamma^{\prime}$ precipitates of $0.5 \mu \mathrm{m}$ average size (Fig.1a). The raft-like $\gamma^{\prime}$ microstructure, perpendicular to the applied stress axis, was obtained adopting a thermomechanical treatment (TMT) of $24 \mathrm{~h}$ at $1050^{\circ} \mathrm{C}$ under a stress of $120 \mathrm{MPa}$ in vacuum (Fig. 1b) of the ST material.

SEN specimens with rectangular cross section of $12 \mathrm{~mm}$ by $4.5 \mathrm{~mm}$ and starter notch $1 \mathrm{~mm}$ deep with $0.05 \mathrm{~mm}$ radius at the crack tip machined by electrical discharge device were used after fatigue precracking at room temperature, at $10 \mathrm{~Hz}$ under the same load conditions used for the subsequent high temperature tests. Typical precracked surfaces along $\{111\}$ planes are reported in Fig. 2 confirming that octahedral slip system is active at room temperature (13). The influence of secondary crystalline orientation along the direction of the crack propagation has been analyzed using $\langle 100\rangle,\langle 210\rangle$ and $<110\rangle$ specimens loaded in the $<001\rangle$ direction.

The fatigue tests were carried out on a servohydraulic testing machine in load control at 750 and $950^{\circ} \mathrm{C}$ in air and in vacuum $\left(10^{-3} \mathrm{~Pa}\right)$ using triangular wave loading $(\mathrm{R}=0.05)$ at the frequency of $4 \mathrm{~Hz}$. Tests at $950^{\circ} \mathrm{C}$ have also been performed adding a $5 \mathrm{~s}$ hold time at the maximum load of 5,880 $\mathrm{N}$ to the triangular wave both in air and in vacuum, always within the linear elastic fracture mechanics frame. Crack length was measured using the d.c. potential drop technique and the crack growth rates were calculated adopting the incremental polynomial procedure.

The fractured specimens have been sectioned parallel to the applied stress and crack propagation directions and prepared by standard metallographic techniques in order to observe the relationship between crack growth and microstructure.

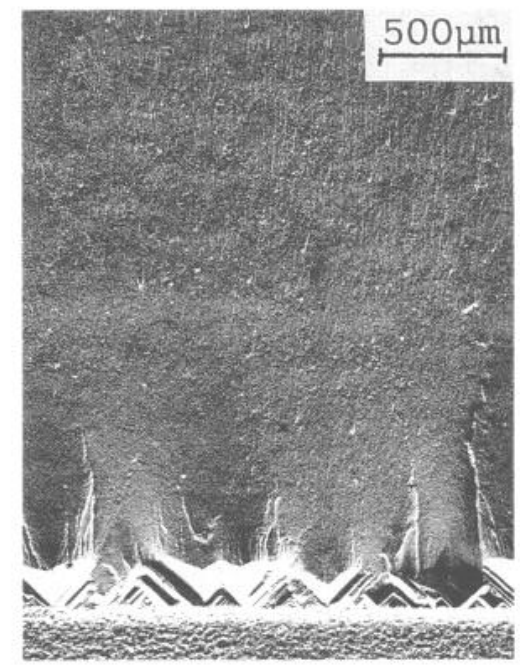

a

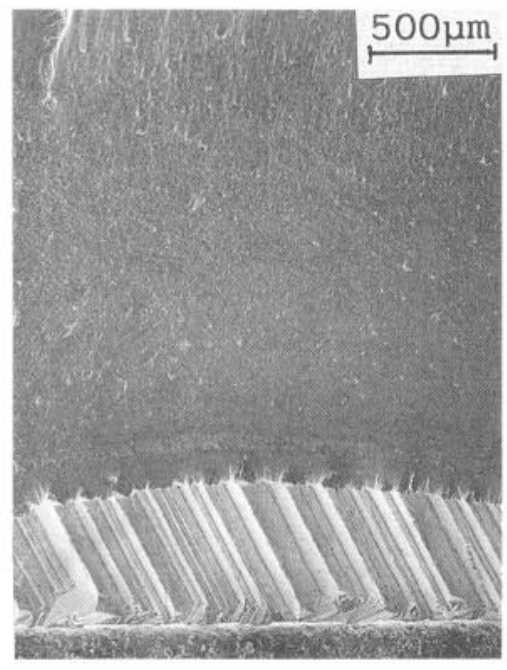

b

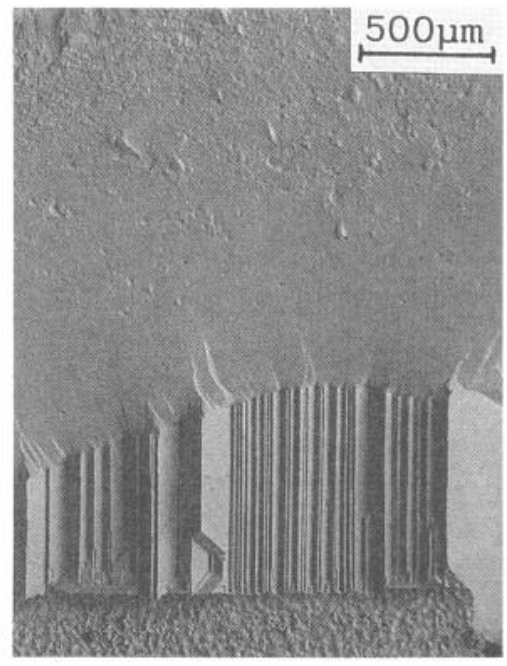

C

Figure 2 - Room temperature precracking along $\{111\}$ planes and $950^{\circ} \mathrm{C} \mathrm{FCP}$ at $4 \mathrm{~Hz}$ : a) $<100>$, b) $<210>$, and c) $<110>$ secondary orientation. 


\section{Experimental Results}

Secondary Orientation Effect. The influence of secondary orientation on ST material FCP rate at $950^{\circ} \mathrm{C}$ and $4 \mathrm{~Hz}$ triangular loading is reported in Fig. 3. The results show the lowest values of FCP rate for cracks propagating along $\langle 110\rangle$ while $\langle 100\rangle$ is confirmed to be the weakest direction with an average factor 6 faster propagation. The $<210>$ direction consistently shows intermediate FCP rate values. At this temperature the orientation effect is relevant but smaller than the one observed at $650^{\circ} \mathrm{C}$ on the same alloy (9). In the $950^{\circ} \mathrm{C}$ tests with $5 \mathrm{~s}$ hold time at maximum load the influence of secondary orientation on FCP rates is similar to that observed in high frequency triangular wave shape tests: the $<100\rangle$ propagation is about 4 times faster than propagation along $<110\rangle$.

Microstructure and Temperature Effect. The FCP rates at $4 \mathrm{~Hz}$, and $750^{\circ} \mathrm{C}$ and $950^{\circ} \mathrm{C}$ are reported in Fig. 4 for the two different microstructures. A marked decrease of FCP rate of ST material appears when temperature is increased from 750 to $950^{\circ} \mathrm{C}$. Comparing these data with data at $650^{\circ} \mathrm{C}$ from Defresne and Rémy (9), also plotted in Fig. 4, although their ageing heat treatment was slightly different, the highest FCP rates appear at $750^{\circ} \mathrm{C}$ while 650 and $950^{\circ} \mathrm{C}$ data are not much different. This behaviour is also consistent with the conclusions of Chan and Leverant (14) that found limited temperature effect on FCP rate of MAR-M 200 single crystal between room temperature and $982^{\circ} \mathrm{C}$ in the 10 to $20 \mathrm{~Hz}$ frequency range. At $950^{\circ} \mathrm{C}$ the TMT material does not behave much differently than at $750^{\circ} \mathrm{C}$, appearing less resistant to FCP than the ST material.

The fracture surfaces show in general a macroscopically flat non crystallographic propagation perpendicular to the applied stress, Fig. 2. At $750^{\circ} \mathrm{C}$ and high $\triangle \mathrm{K}$ fatigue striations and facets on $\{111\}$ planes became evident and at $\Delta K$ values above $50 \mathrm{MPa} \vee \mathrm{m}$ all the propagation facets occurred on $\{111\}$ planes for both ST and TMT materials showing a roof-top pattern (Fig. 5). At $950^{\circ} \mathrm{C}$ different fracture morphologies are apparent depending on the microstructure. In the ST material at low $\Delta \mathrm{K}$ the crack grows along (001) planes. When $\Delta \mathrm{K}$ increases secondary cracks and some crystallographic facets appear, specially at the near-surface region and this type of fracture prevails at high $\Delta K$ (Fig. 6a). At low stress intensity range the fracture surface of the TMT material is flat (Fig. 6b) while at high $\triangle \mathrm{K}$ values some asperities, but without any crystallographic features, can be found on the fracture surface.

Time Dependent Effects. The results of triangular and hold time tests at $950^{\circ} \mathrm{C}$ in air and vacuum are reported in Fig. 7 for ST material. A similar but less complete graph for TMT material is shown in Fig. 8. For both heat treatments, air environment causes a marked decrease of

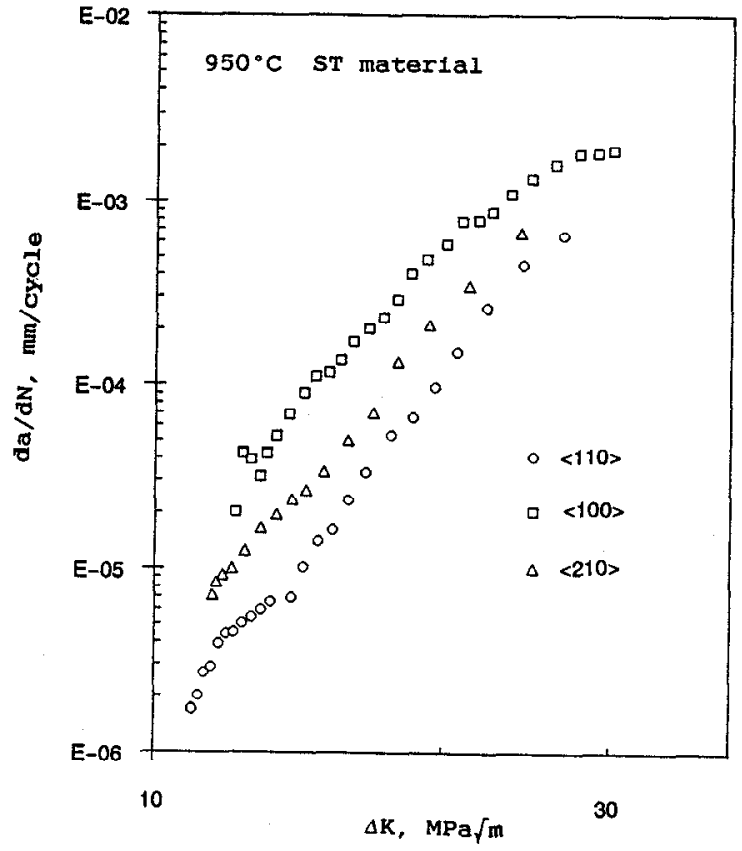

Figure 3 - Influence of secondary orientation on FCP rates. 


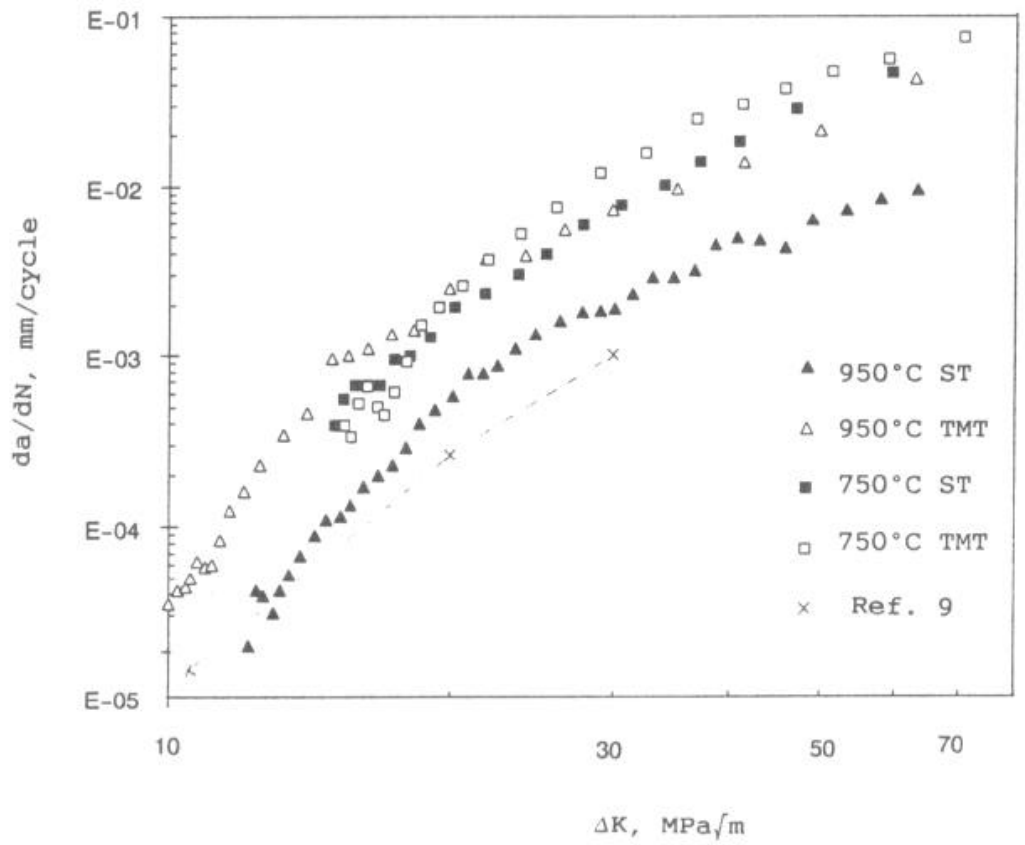

Figure 4 - Temperature effect on $4 \mathrm{~Hz}$ FCP rates of ST and TMT materials; data from Ref. 9 are also reported.

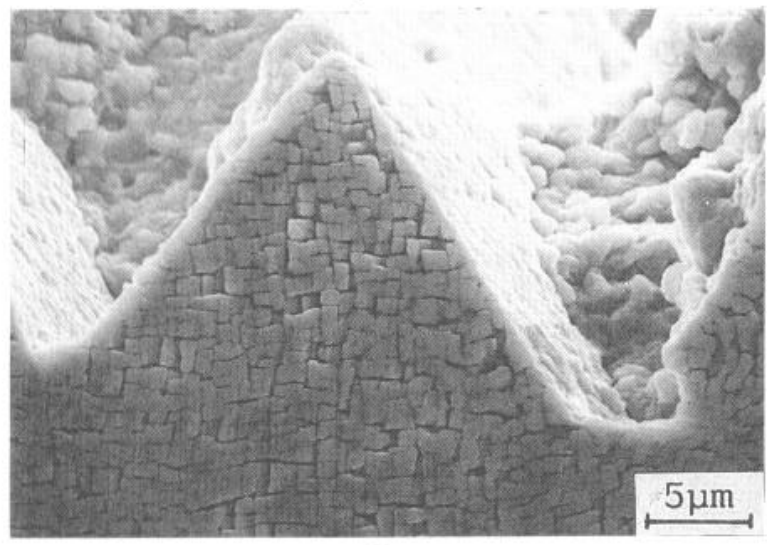

a

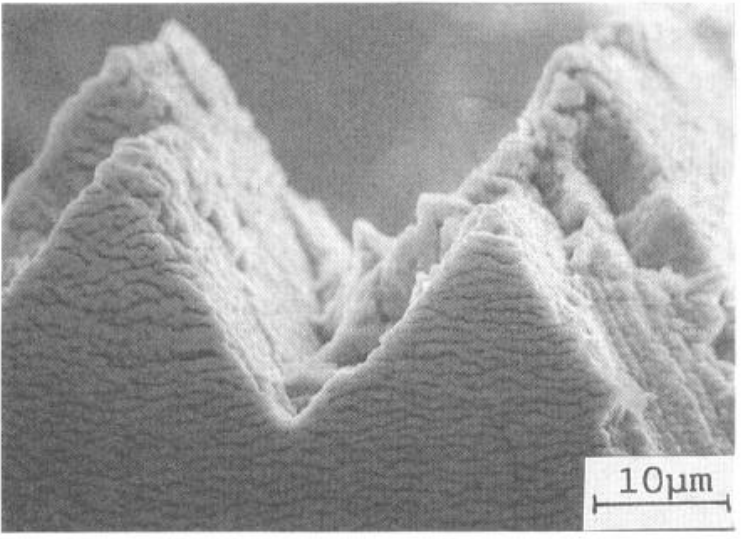

b

Figure 5 - Fracture surfaces along $\{111\}$ planes at $750^{\circ} \mathrm{C}$ and high $\triangle \mathrm{K}$ of cuboidal $\gamma^{\prime}$ (a) and raft-like $\gamma^{\prime}$ materials (b).

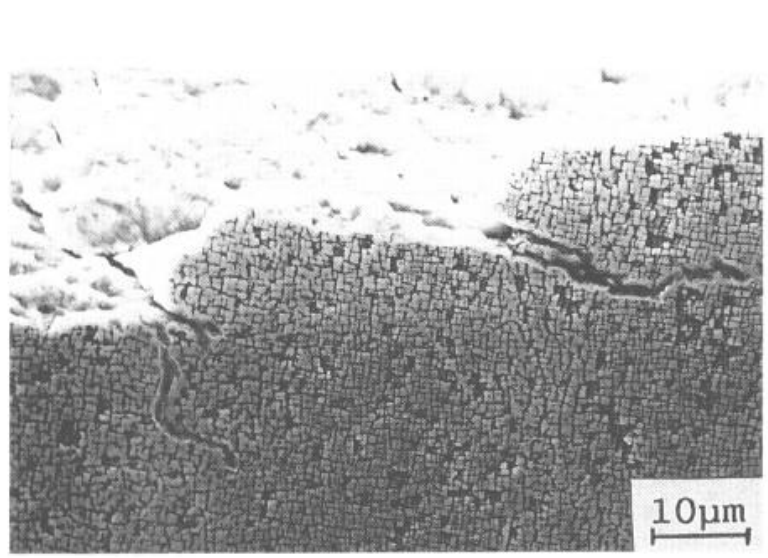

a

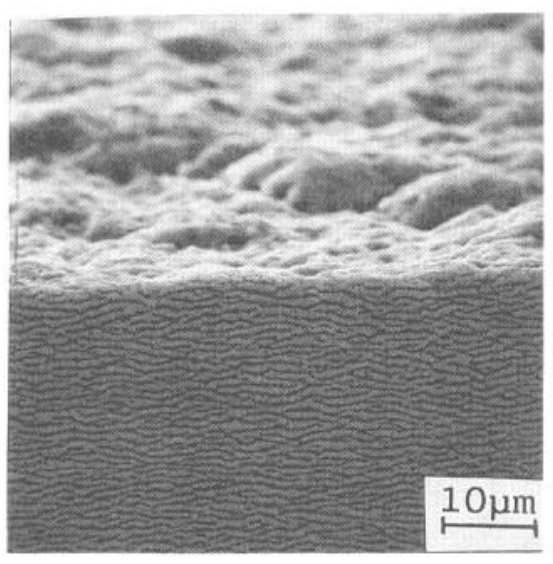

b

Figure 6 - Fracture surfaces at $950^{\circ} \mathrm{C}$ with secondary cracks in the ST material (a) and without secondary cracks in TMT material (b). 


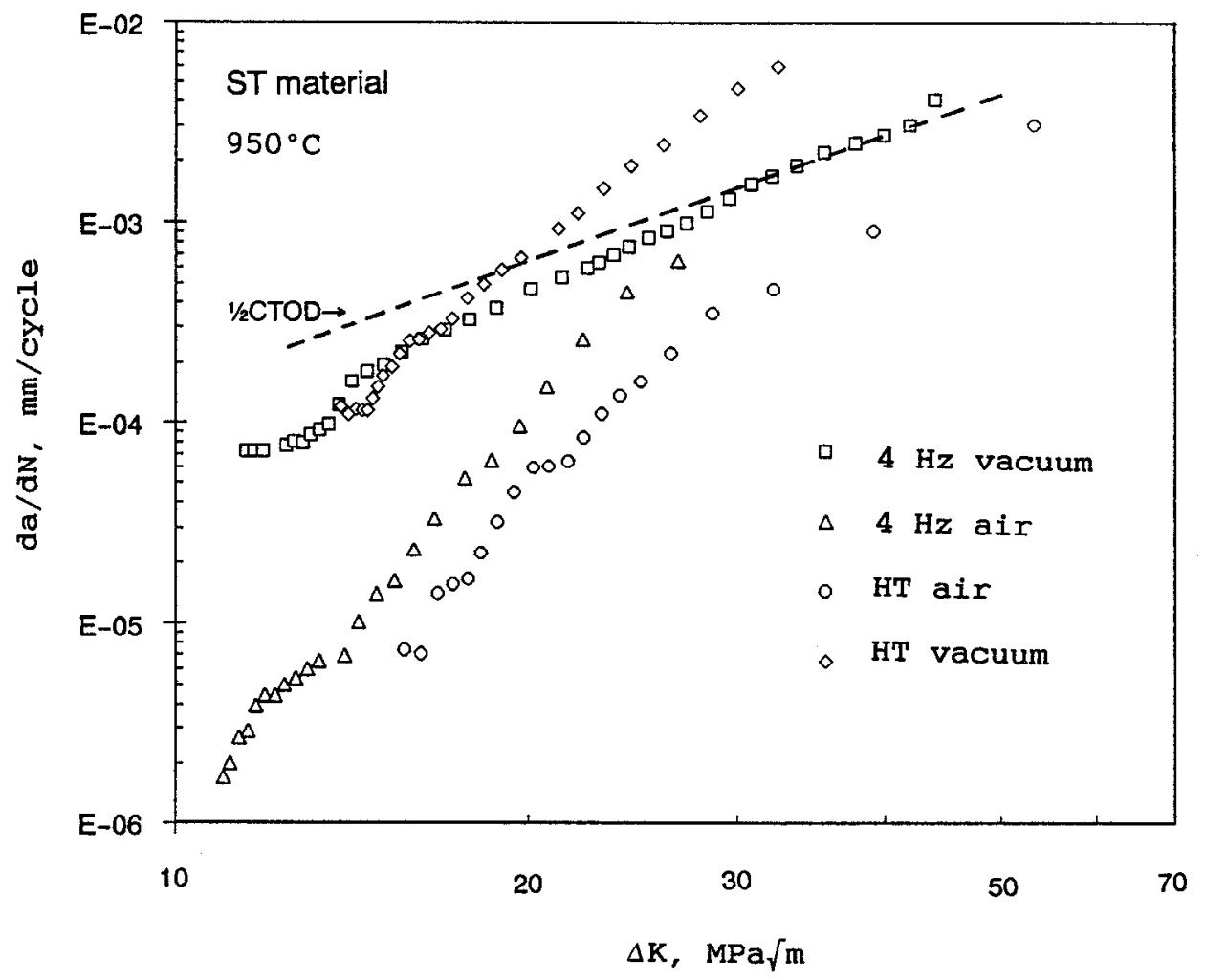

Figure 7 - Hold time (HT) and environment effects on FCP rates in ST matcrial ( $<110>$ secondary orientation).

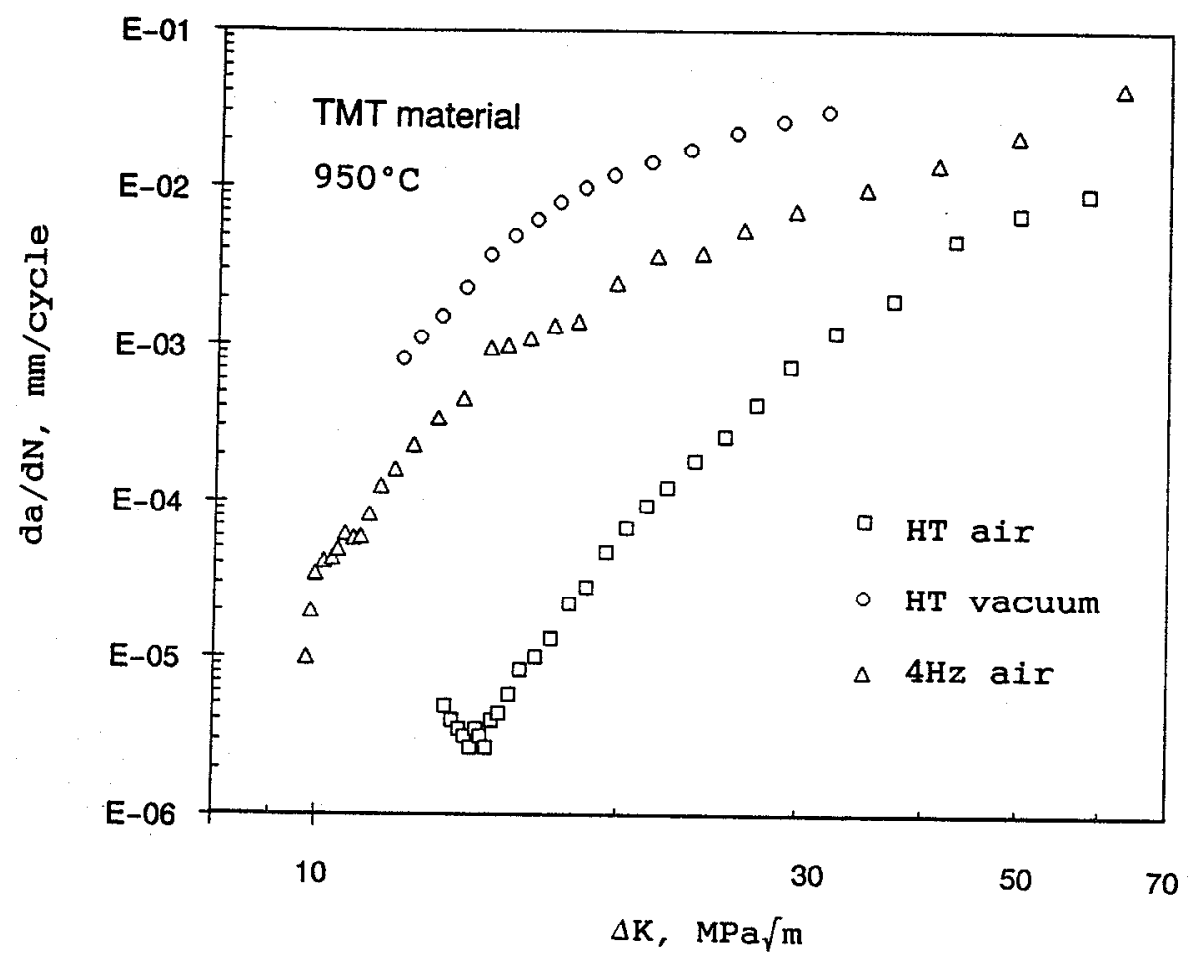

Figure 8 - Hold time (HT) and environment effects on FCP rates in TMT material $(<100>$ secondary orientation). 


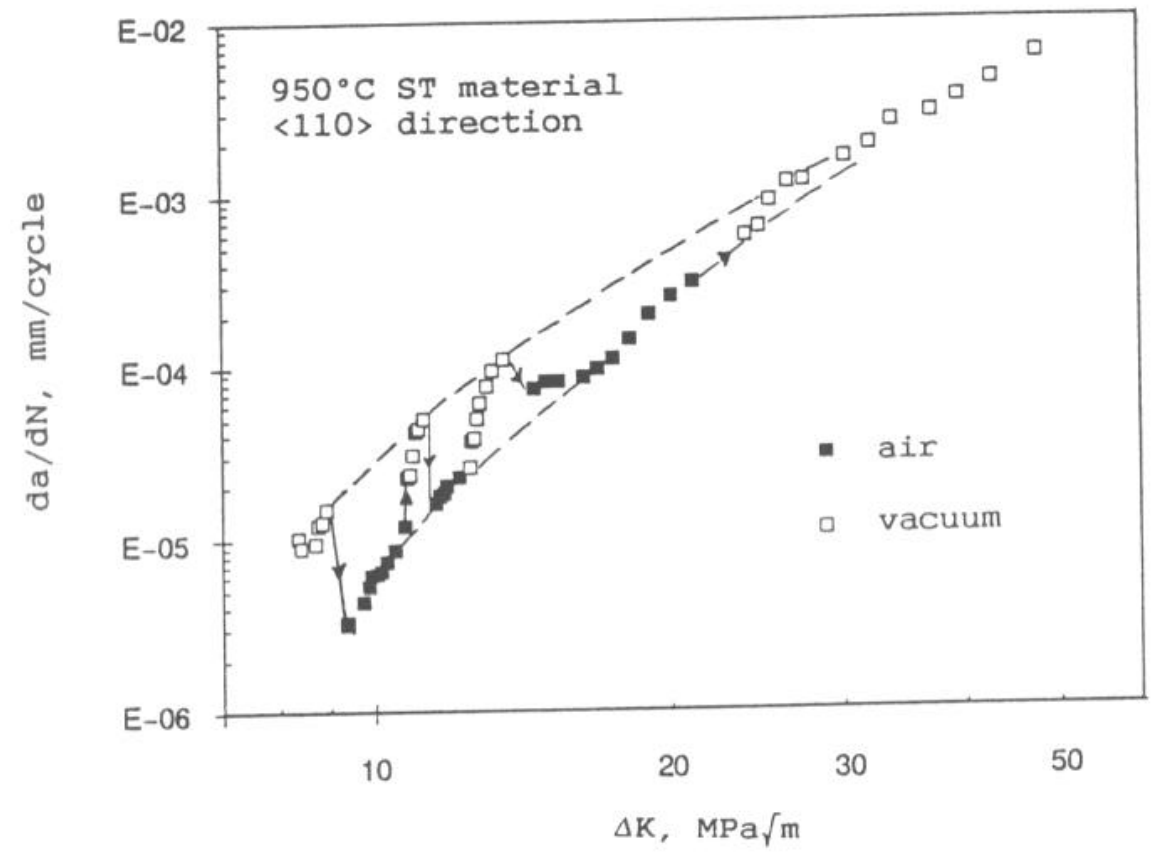

Figure 9 - Effect of repeatedly changed environment from vacuum to air and vice versa on a hold time FCP rate.

the FCP rates, specially when hold time is added. A qualitatively similar behaviour has been observed in ODS MA 6000 superalloy, since FCP rates at $850^{\circ} \mathrm{C}$ were slower in air than in vacuum at 10 and $0.01 \mathrm{~Hz}$ triangular loading (15). When environment is repeatedly changed, from vacuum to air and vice versa, during a single test at $950^{\circ} \mathrm{C}$ applying $5 \mathrm{~s}$ hold time the FCP behaviour confirms slower propagation in air than in vacuum, sometimes showing a transient stage, Fig. 9. The fracture surface of this specimen appears in Fig. 10, clearly marked by alternating vacuum and air, where darker areas correspond to crack front propagation in air.

\section{Discussion}

Test temperature has a strong effect on mechanisms of FCP in CMSX-2. At room temperature the propagation is crystallographic indicating that the plastic deformation is heterogeneous, localized along octahedral $\{111\}$ slip planes, as observed in the precracked regions, Fig. 2. At high temperature thermal activation of dislocations produces a more homogeneous plastic deformation, thereby fracture surfaces do not present crystallographic features. It has been reported that crystallographic propagation is found up to about $760^{\circ} \mathrm{C}$ in this class of materials (13).

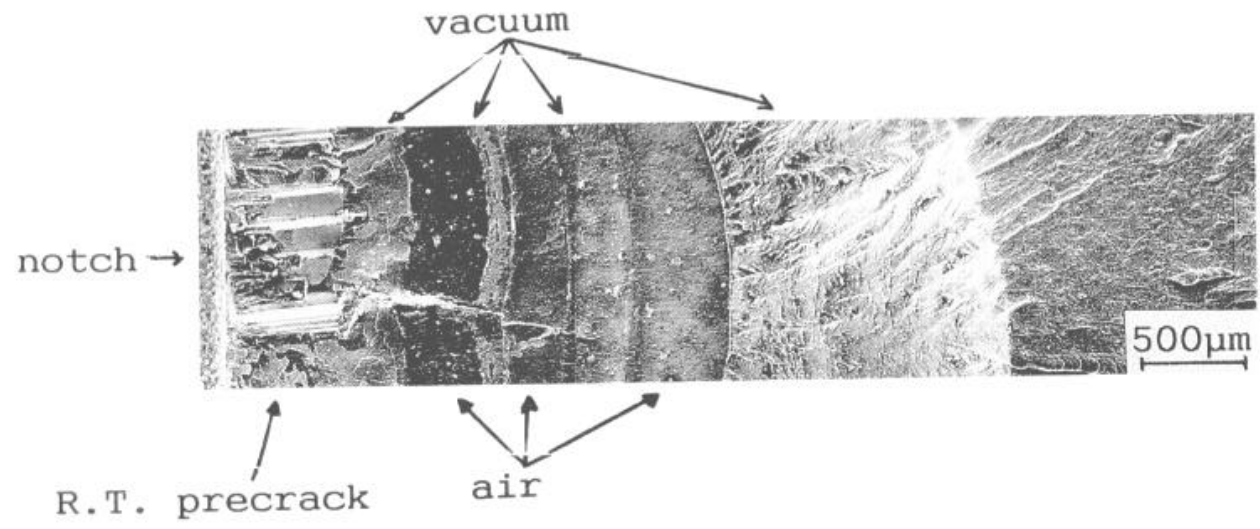

Figure 10 - Fracture surface of the test reported in Fig. 9. 
Confirming the reported behaviour, some crystallographic features are present on the fracture surfaces at $750^{\circ} \mathrm{C}$ and high $\triangle \mathrm{K}$ indicating that plastic deformation is still localized on $\{111\}$ slip planes, Fig. 5, while secondary cracks and deflections of the main crack along $\gamma^{\prime}$ channels perpendicular to the crack, copiously present on the fracture surface at $950^{\circ} \mathrm{C}$, Fig. $6 \mathrm{a}$, support the hypothesis that more homogeneous deformation, although mainly confined within $\gamma$ matrix, takes place at high temperature. These different fracture morphologies can explain the slower FCP rate at $950^{\circ} \mathrm{C}$ in the cuboidal $\gamma^{\prime}$ microstructure. The raft-like $\gamma^{\prime}$ microstructure is perpendicular to the applied load and tends to confine crack propagation within the matrix. In fact in TMT material at $950^{\circ} \mathrm{C}$ no branching of the crack is observed, the fracture surface being very flat, Fig. 6b, and only rarely cutting through the $\gamma^{\prime}$ rafts.

It has been established that in general high temperature cyclic crack propagation can be separated into time-dependent and cycle dependent components, the former being creep and/or environment controlled, while the cycle-dependent part is regarded as the pure fatigue component. At elevated temperature the inclusion of a hold time in a fatigue cycle for polycrystalline materials results in increasing crack growth rates at higher stress intensities and in retarding crack propagation in the near threshold region $(16,17)$. These results can be rationalized within fatigue-creep-environment interactions: at low $\triangle \mathrm{K}$, i.e. at threshold region, oxide induced closure may reduce the effective $\triangle \mathrm{K}$ and retard crack propagation, while at high $\triangle \mathrm{K}$ oxide layer in air is not thick enough compared to the crack tip opening displacement (CTOD) to cause significant crack closure, and oxidation enhanced embrittlement forms at grain boundaries within the plastic zone during each hold period, thereby accelerating crack propagation. The FCP rate curves shown in Fig. 7 are discussed here within creep-fatigue-environment interactions frame: the $4 \mathrm{~Hz}$ vacuum curve represents the pure fatigue component of the crack propagation phenomenon that is quite close to the CTOD model prediction (18), shown by the dashed line in Fig. 7. The $4 \mathrm{~Hz}$ curve in air is more than an order of magnitude slower at the smallest $\Delta \mathrm{K}$. This FCP rate gap continuously decreases with increasing $\triangle \mathrm{K}$ and the two curves finally converge at high $\triangle \mathrm{K}$, consistently with an oxide induced closure process. When the hold time is added in vacuum no creep effect appears at low $\Delta \mathrm{K}$, but when $\Delta \mathrm{K}$ is increased the hold time curve and the triangular curve continuously diverge. The difference between these two curves in vacuum represents the creep and/or creep-fatigue interaction contribution to the FCP rate. Hold time FCP rate curve in air appears still slower than the triangular curve for all the $\triangle K$ range explored indicating that: i) oxide closure is more effective, and ii) oxide blunting of the crack tip occurs, Fig. 11, when hold time is added. These two phenomena could also explain why no creep and/or creep-fatigue acceleration is clearly observed in the hold time curve in air.

Experimental support to oxide closure hypothesis was sought in observing the variation of the oxide thickness on the fracture surface, Fig. 12. The asymptotic value of the thickness at maximum distance from the notch could be representative of crack tip situation due to the short time exposure of this zone at elevated temperature. The standard material, tested at $5 \mathrm{~s}$ hold time, had the thickest oxide layer while rafted material without hold period had the thinnest oxide. This oxide thickness was approximately $10 \%$ and $30-60 \%$ of $1 / 2$ CTOD value at triangular and hold time conditions, respectively, at low $\triangle \mathrm{K}$; at high $\triangle \mathrm{K}$ it became $2 \%$ at $4 \mathrm{~Hz}$ where closure mechanism is not effective anymore and $10-20 \%$ in hold time tests.

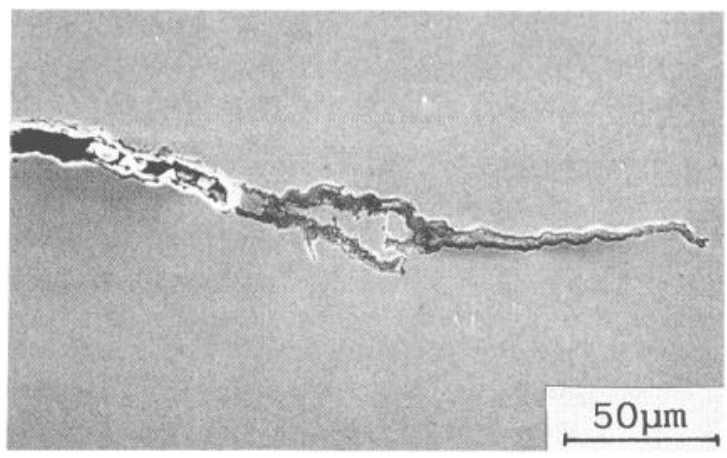

Figure 11 - Oxidized secondary crack after FCP at $950^{\circ} \mathrm{C}$ and hold time in ST material. 


\section{Conclusions}

This study of FCP behaviour in $<001>$ loaded single crystal of CMSX-2 superalloy has shown: $<100>$;

i) FCP rates at $950^{\circ} \mathrm{C}$ are much slower along $<110>$ than along the fastest direction

ii) when temperature is increased from 750 to $950^{\circ} \mathrm{C}$ FCP rate decreases in cuboidal $\gamma^{\prime}$ material while only a slight FCP rate change is observed in raft-like $\gamma^{\prime}$ material;

iii) at $950^{\circ} \mathrm{C}$ both oxidation and creep processes at crack tip are operative; the effect of oxidation is to slow down FCP rates through oxide induced closure mechanisms at low $\Delta \mathrm{K}$ and possibly through crack tip blunting; on the other hand, the effect of creep is to enhance $\mathrm{FCP}$ rates at high $\Delta \mathrm{K}$ values;

iv) due to the absence of the environmental effect the vacuum FCP rates, that simulate growth of cracks starting and propagating inside the component, show higher values, especially when hold time is applied;

v) cracks in material after short service in high temperature creep regime propagate faster than in standard microstructure material at $950^{\circ} \mathrm{C}$.

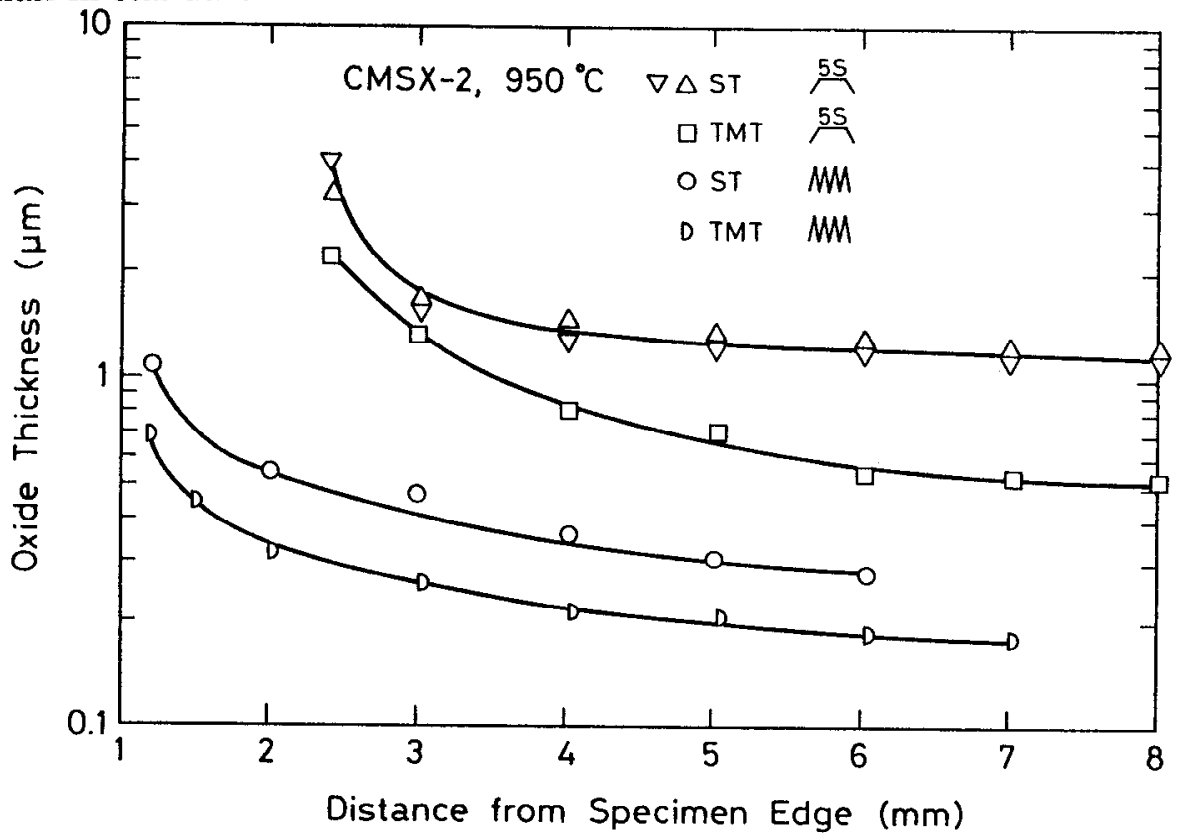

Figure 12 - Oxide thickness on fracture surfaces of FCP specimens after triangular loading with and without hold time.

\section{References}

1) F. Gabrielli, M. Marchionni, and G. Onofrio, "Time Dependent Effect on High Temperature Low Cycle Fatiguc and Fatiguc Crack Propagation of Nickel Base Superalloys", (Paper presented at the ICF7, Houston, Texas, 20 March 1989), Pergamon Press 1149-1163.

2) J.S. Crompton and J.W. Martin, "Crack Growth in a Single Crystal Superalloy at Elevated Temperature", Metall. Trans., 15A (1984), 1711-1719.

3) D.L. Anton, "Low Cycle Fatigue Characteristics of $<001>$ and Randomly Aligned Superalloy Single Crystal", Acta Met., 32, N.10 (1984), 1669-1679.

4) P. Caron et al.,"On the Iiffects of Heat Treatments on the Creep Behaviour of a Single Crystal Superalloy", Scripta Metall., 20 (1986), 875-880. 
5) J. Hammer and H. Mughrabi, "High-Temperature Creep and Microstructure of the Monocrystalline Nickel-Base Superalloy SRR 99", (Paper presented at Advanced Materials and Processes, EUROMAT'89, Aachen, D, 1989), DGM, 1 (1990), 445-450.

6) V. Lupinc et al., "Influenza di un trattamento termomeccanico sulla resistenza a creep e alla propagazione di cricca per fatica in una superlega di nichel monocristallina", (Paper presented at the XII Convegno Nazionale Trattamenti Termici, Salsomaggiore, I, 1989), AIM, Milano, 73-82.

7) C. Howland and C.W. Brown, "The Effect of Orientation on Fatigue Crack Growth in a Nickel-Based Single Crystal Superalloy", (Paper presented at the 2nd International Conference on Fatigue and Fatigue Thresholds, Birmingham, UK, 3 Sept. 1984), 1349-1359.

8) A. Diboine, J.M. Peltier, and R.M. Pelloux, "Fatigue Crack Propagation in a Single Crystal Nickel Base Superalloy", (Paper presented at High Temperature Fracture Mechanisms and Mechanics, ECF6, 1987, Dourdan, F), EGF (1990), 421-446.

9) A. Defresne and L. Rémy, "Fatigue Behaviour of CMSX-2 Superalloy <001> Single Crystal at High Temperature - II: Fatigue Crack Growth", Mat. Sci. and Eng., A129 (1990), 5564.

10) G. Onofrio et al. "Influence of Time Dependent Mechanisms on Fatigue Crack Growth in a Single Crystal Nickel Base Superalloy" (Paper presented at Fracture Behaviour and Design of Materials and Structures, ECF8, Torino, Italy, 1 Oct. 1990), EMAS, 1231-1236.

11) S.H. Ai, et al., "Influence of Microstructure on Fatigue Crack Growth Behaviour of a Single Crystal Nickel Base Superalloy" (Paper presented at the Fourth Int. Conference on Fatigue and Fatigue Thresholds, Honolulu, Hawaii, 15 July 1990), MCEP, 249-254.

12) S.H. Ai, V. Lupinc, and G. Onofrio, "Fatigue Crack Propagation Behaviour of CMSX-2 Single Crystal Superalloy" (Paper presented at Mechanical Properties/Materials Design CMRS, 1990, Beijing), Elsevier Sci. Pub.s, 5 (1991), 129-134.

13) G.R.Leverant and M.Gell, "The Influence of Temperature and Cyclic Frequency on the Fatigue Fracture of Cube Oriented Nickel Base Superalloy Single Crystal", Metall. Trans., 6A, (1975), 367-371.

14) K.S. Chan and G.R. Leverant, "Elevated Temperature Fatigue Crack Growth Behaviour of MAR-M200 Single Crystals", Metall. Trans., 18A (1987), 593-602.

15) F. Gabrielli, G. Vimercati and V. Lupinc, "Environmental Effects on High Temperature Fatiguc Crack Growth Bchaviour of Nickcl Base Supcralloys" ( Paper presented at the Int. Conf. on Mechanical Behaviour of Materials-V, Beijing, China, 3 June 1987), 811-818

16) R.O. Ritchie and S. Suresh, "Some Considerations on Fatigue Crack Closure at Near Threshold Stress Intensities Due to Fracture Surface Morphology", Matall. Trans., 13A (1982), 937-940.

17) M.C. Murphy, "The Engineering Fatigue Properties of Wrought Copper", Fatigue Engng. Mater. Struct., 4 (1981), 199-234.

18) F.A. McClintock, AST'M STP 415, (ASTM 1967), 170. 